\title{
CHANGING TRENDS IN OCCURRENCE OF PLACENTA PREVIA
}

\author{
P. Rajini ${ }^{1}$, G. Shobha ${ }^{2}$, Laxmi Prasanna ${ }^{3}$ \\ ${ }^{1}$ Assistant Professor, Department of Obstetrics \& Gynaecology, Gandhi Medical College/Hospital. \\ 2Professor Incharge, Department of Obstetrics \& Gynaecology, Gandhi Medical College/Hospital. \\ ${ }^{3}$ Assistant Professor, Department of Obstetrics \& Gynaecology, Gandhi Medical College/Hospital.
}

ABSTRACT

\section{BACKGROUND}

To find out the changing trends in occurrence of placenta previa cases.

\section{MATERIALS AND METHODS}

It is a retrospective study of 82 cases of pregnancy beyond 28wks of gestation, complicated with placenta previa during 1 year period at Department of OBG, Gandhi Hospital.

\section{RESULTS}

Total No. of placenta previa cases were 82. Incidence comes to be $0.9 \%$. Predisposing factors causing placenta previa where age, parity, previous h/o D \& C, MTP'S, LSCS, or any other gynaec surgeries or any injury were evaluated. In this study $70.7 \%$ of cases were found to be in younger age group 20-24 years. Primi para contributing $29.2 \%$ without any predisposing factors. This is clearly showing increasing in the incidence of placenta previa in primigravida. This needs conformation by doing a larger study. The no of previa with previous LSCS were 26 (31\%), abortions (12\%), D \& C were 6 (7.3\%), hysterotomy were 2 (2.4\%).

\section{KEY WORDS}

Placenta Previa, Parity, Ultrasound, Previous Caesarean Section.

HOW TO CITE THIS ARTICLE: Rajini P, Shobha G, Prasanna L. Changing trends in occurrence of placenta previa. J. Evolution Med. Dent. Sci. 2016;5(19):933-935, DOI: 10.14260/jemds/2016/217

\section{INTRODUCTION}

Placenta previa is an obstetric complication in which the placenta is inserted partially or wholly in the lower uterine segment. ${ }^{1}$ It is a leading cause of antepartum haemorrhage (V bleeding). It affects approximately $0.3 \%$ or 1 case per 300 to 400 deliveries. It was reported to be almost 1 in 300 deliveries in USA in 2003 (Martin, 2005) the frequency at Parkland Hospital from 1988 through 2012 was approximately 1 in 360 for 366,000 births. These reported frequencies are remarkably similar considering the lack of precision in definition and classification. ${ }^{2}$ In the last trimester of pregnancy the isthmus of the uterus stretch and forms the lower segment.

Though the causes of placenta previa were commonly like previous h/o D \& C. ${ }^{3}$ LSCS. $^{4}$ myomectomy. ${ }^{5}$ age factor, repeated abortions, multi gravid, rarely seen in primi gravida. Now this study showed that there is increased in incidence of previa as well as increased in primi gravida. Exact cause of placenta previa is unknown. It is hypothesized to be related to abnormal vascularisation of the endometrium caused by scarring or atrophy from previous trauma, surgery, or infection. These factors may reduce differential growth of lower segment, resulting in less upward shift in placental position as pregnancy advances. ${ }^{6}$ Term migration is clearly a misnomer, because decidual reaction by chorionic villi on either side of cervical OS persists.

Financial or Other, Competing Interest: None.

Submission 23-01-2016, Peer Review 19-02-2016,

Acceptance 24-02-2016, Published 04-03-2016.

Corresponding Author:

Dr. P. Rajini,

Department of Obstetrics \& Gynaecology,

Gandhi Medical College/Hospital,

Hyderabad-500003.

E-mail:dr.shobhagumdal@gmail.com,swapna.arza@gmail.com DOI: $10.14260 /$ jemds/2016/217
There is a differential growth of upper and lower uterine segments as pregnancy advances. With great upper uterine blood flow placental growth more likely will be towards the fundus-trophotropism. So many of those placentas that migrate most likely never were circumferentially implanted with true villous invasion that reached cervical OS. Finally, a low-lying placenta is less likely to migrate within a uterus with a prior caesarean hysterotomy scar. Traditionally, four grades of placenta previa were used, however now it is more common to simply differentiate between 'Major' and 'Minor' cases.7

In minor degree of placenta previa, placenta is in the lower segment, lower edge does not cover the internal OS. In major degree of placenta previa, it is in the lower segment and also covers the internal OS. Previa can be confirmed with an ultrasound. Transvaginal ultrasound has superior accuracy as compared to transabdominal one, thus allowing measurement of distance between placenta and cervical os. This has rendered traditional classification of placenta previa obsolete.8,9,10,11 False positives may be due to following reasons. ${ }^{12}$ Overfilled bladder compressing lower uterine segment. Myometrial contraction simulating placental tissue in abnormally low location

\section{AGE}

The frequency of previa increases with maternal age.

At Parkland Hospital this incidence increases from a low rate of approxmately1 in 1660 for women 19yrs or younger to almost 1 in 100 for women older than 35yrs. The FASTER TRIAL, which included more than 36000 women cited the frequency of previa to be $0.5 \%$ for women younger than $35 \mathrm{yrs}$ compared to $1.1 \%$ in those older than 35yrs (ClearlyGoldman2005) in present study we observed that the incidence was high for women between 20-24yrs which accounts to be $29.2 \%$. All cases were below $35 y$ rs only. 
So in contrast to previous studies younger women are also at risk of previa, where cause might be early marriages or some other unknown reasons that have to be further studied.

\begin{tabular}{|c|c|}
\hline $20-24$ & 20 \\
\hline $25-29$ & 6 \\
\hline $30-35$ & 2 \\
\hline \multicolumn{2}{|c|}{ Table 1: Age } \\
\hline
\end{tabular}

\section{PARITY}

The risk for previa increase with parity. Exact cause of placenta praevia is unknown. It is hypothesized to be related to abnormal vascularisation of the endometrium caused by scarring or atrophy from previous trauma, surgery, or infection. These factors may reduce differential growth of lower segment, resulting in less upward shift in placental position as pregnancy advances.

\begin{tabular}{|c|c|}
\hline Primis & $24(29.2 \%)$ \\
\hline $2-4$ & $54(65.8 \%)$ \\
\hline$>=5$ & $4(4.8 \%)$ \\
\hline \multicolumn{2}{|c|}{ Table 2: Parity } \\
\hline
\end{tabular}

In present study 24 cases were in primis, multies 54 $(65.8 \%)$ and grandmulties were $4(4.8 \%)$. Incidence is increasing with parity. At our center total no. Of deliveries were 9127 . So multies accounts to be $1.03 \%$.

\begin{tabular}{|c|c|c|c|c|}
\hline $\begin{array}{c}\text { Total No. } \\
\text { of } \\
\text { Deliveries }\end{array}$ & $\begin{array}{c}\text { Total } \\
\text { No. of } \\
\text { Primis }\end{array}$ & $\begin{array}{c}\text { Total } \\
\text { No. of } \\
\text { Multies }\end{array}$ & $\begin{array}{c}\text { Total } \\
\text { No. of } \\
\text { LSCS }\end{array}$ & $\begin{array}{c}\text { Total No. } \\
\text { of } \\
\text { Placenta } \\
\text { Previa }\end{array}$ \\
\hline 9127 & 3509 & 5618 & 3434 & 82 \\
\hline \multicolumn{4}{|c|}{ Table 3: Parity Distribution } \\
\hline
\end{tabular}

Previous caesarean section: 26 cases $(0.76 \%)$ of placenta previa cases had previous caesarean section. $80 \%$ of cases were anterior placentas, out of all these one had adherent placenta resulting in caesarean hysterectomy. Incidence of previa in such cases is $0.76 \%$. In present study $24 \%$ of cases were with 1 caesarean section $\& 17 \%$ was with 2 sections.

A meta-analysis showed that the rate of placenta previa increases with increasing numbers of caesarean deliveries with a rate of $1 \%$ after 1 caesarean delivery, $2.8 \%$ after 3 caesareans, and as high as $3.7 \%$ after 5 caesarean deliveries. ${ }^{1}$

\begin{tabular}{|c|c|c|}
\hline No. C. S & $\begin{array}{c}\text { No. of Placenta } \\
\text { Previa }\end{array}$ & $\begin{array}{c}\text { \% of Placenta } \\
\text { Previa }\end{array}$ \\
\hline 1 & 20 & 24 \\
\hline 2 & 6 & 17 \\
\hline 3 & 0 & 0 \\
\hline \multicolumn{2}{|r|}{ Table 4: Distribution as per Previous C. S. } \\
\hline
\end{tabular}

\begin{tabular}{|c|c|c|c|c|c|c|}
\hline $\begin{array}{c}6 \\
\text { months }\end{array}$ & $\begin{array}{c}\text { Upto } \\
1 y r .\end{array}$ & $\begin{array}{c}\text { Upto } \\
11 / 2 \\
\text { yr. }\end{array}$ & $\begin{array}{c}\text { Upto } \\
2 \text { yrs. }\end{array}$ & $\begin{array}{c}\text { Upto } \\
3 y r s\end{array}$ & $\begin{array}{c}\text { Upto } \\
4 y r s .\end{array}$ & $\begin{array}{c}\text { Upto } \\
5 y r s .\end{array}$ \\
\hline 3 & 25 & 25 & 2 & 1 & 1 & 1 \\
\hline \multicolumn{7}{|c|}{ Table 5: Duration between Previous Procedure and } \\
Pregnancy with Placenta Previa
\end{tabular}

This present study shows that as duration between the previous procedure and present pregnancy with previa is indirectly related to occurrence of placenta previa. About $67 \%$ of cases were within $2 y$ rs period and rest beyond 2 years. This gives information that minimum period between any uterine procedure and pregnancy should be at least 2 yrs. to reduce this association.

\section{Abortions}

Out of 82 cases of placenta previa cases 10 cases were with h/o abortions. 2 were with medical methods and 8 underwent check curettage following incomplete abortion. There were 6 placenta previa cases with h/o D\&C done. Exact reason for this procedure is unknown, 2 out of 6 were done for infertility.

2 cases out of 82 placenta previa. One case had h/o injury by Road Traffic Accident, where uterine tear was repaired earlier, in that case hysterectomy have to be performed for severe bleeding. Other case had hysterotomy performed earlier, developed placenta previa in next pregnancy. Emergency pre term LSCS was done for profuse bleeding per vagina.

\section{CONCLUSIONS}

Due to newer technologies and new procedures performed as part of treatment for infertility, for uterine anomalies, there is increase in incidence of placenta previa. Early diagnosis of placenta previa is also contributing factor for increasing incidence.

We can say that there is a changing trend in occurrence of placenta previa from multies to primis. There is increasing number of primigravida with placenta previa were exact cause is not known.

There should be a large study to know the exact causes resulting in placenta previa in primigravida.

\section{REFERENCES}

1. Arulkumaran, edited by Richard Warren, Sabaratnam best practice in labour and delivery. Cambridge: cambridge university press $2009 ; 1^{\text {sted(2 }} 3^{\text {rd }}$ printing.ed);p142-146. ISBN 978-0-521-72068-7.

2. Williams obstetrics. $2014 ; 24^{\text {th }}$ edition:page no-801.

3. Kendrick, Chantal Simon, Hazel Everitt, et al. Oxford handbook of general practice. Oxford: Oxford University Press 2005;2nd ed:p-793. ISBN 9780198565819.

4. Weerasekera DS. Placenta praevia and scarred uterus- an obstetrician's dilemma. Journal of Obstetrics \& Gynaecology 2000;20(5):484-5.

Doi:10.1080/014436100434659. PMID 15512632.

5. Brinsden, Judith Collier, Murray Longmore, et al. Oxford handbook of clinical specialties. Oxford: Oxford University Press 2006;7th ed:p-1970. ISBN 9780198530855.

6. Callander, Kevin P Hanretty. Illustrated by ian ramsden, robin. Obstetrics illustrated edinburgh [etc.]: churchill livingstone 2004; $6^{\text {thed(Reprinted }}$ ed):p-187. ISBN 0443072671.

7. RCOG Guidelines for placenta previa, placenta accreta, vasa preavia- diagnosis and management. Greentop Guideline Jan, 2011;no.27.

8. Oppenheimer LW, Farine D, Ritchie JW, et al. What is a low-lying placenta?. American journal of obstetrics and gynecology 1991;165(4Pt 1):1036-8. doi:10.1016/00029378(91)90465-4. PMID 1951509. 
9. Neale EJ, Rogers MS. Vaginal ultrasound for ruling out placenta previa. Case report. BJOG: an International Journal of Obstetrics and Gynaecology 1989;96(7):881881. doi:10.1111/j.1471-0528.1989.tb03334.x.

10. Smith RS, Lauria MR, Comstock $\mathrm{CH}$, et al. Transvaginal ultrasonography for all placentas that appear to be lowlying or over the internal cervical OS. Ultrasound in obstetrics \& gynecology: the official journal of the International Society of Ultrasound in Obstetrics and Gynaecology 1997;9(1):22-4. doi:10.1046/j.14690705.1997.09010022.x. PMID 9060125.
11. Farine D, Fox HE, Jakobson S, et al. Vaginal ultrasound for diagnosis of placenta previa. American journal of obstetrics and gynecology 1988;159(3):566-9. PMID 3048096.

12. Sutton, David. Textbook of radiology and imaging Edinburgh: Churchill Livingstone 2003; 7 thed:p-1064. ISBN 0443071098. 